\title{
PCR-based rapid genotyping of Stenotrophomonas maltophilia
} isolates

\author{
Emanuela Roscetto $^{\dagger 1}$, Francesco Rocco ${ }^{\dagger 1}$, M Stella Carlomagno1, \\ Mariassunta Casalino ${ }^{2}$, Bianca Colonna ${ }^{3}$, Raffaele Zarrilli ${ }^{4}$ and Pier Paolo Di \\ Nocera*1
}

Address: ${ }^{1}$ Dipartimento di Biologia e Patologia Cellulare e Molecolare, Università Federico II, Via S. Pansini 5, 80131 Napoli, Italy, ${ }^{2}$ Dipartimento di Biologia, Università Roma TRE, Viale Marconi 446 Roma, Italy, ${ }^{3}$ Istituto Pasteur-Fondazione Cenci Bolognetti, Dipartimento di Biologia Cellulare e dello Sviluppo, Università Roma La Sapienza, Via dei Sardi 70 Roma, Italy and ${ }^{4}$ Dipartimento di Scienze Mediche Preventive, Sezione di Igiene, Università Federico II, Via S. Pansini 5, 80131 Napoli, Italy

Email: Emanuela Roscetto - emanuelaroscetto@gmail.com; Francesco Rocco - francesco_rocco@alice.it; M Stella Carlomagno - carloma@unina.it; Mariassunta Casalino - casalino@uniroma3.it; Bianca Colonna - bianca.colonna@uniroma1.it; Raffaele Zarrilli - rafzarri@unina.it; Pier Paolo Di Nocera* - dinocera@unina.it

* Corresponding author †Equal contributors

Published: 24 November 2008

BMC Microbiology 2008, 8:202 doi:10.1 I86/I47|-2180-8-202
Received: 18 June 2008

Accepted: 24 November 2008

This article is available from: http://www.biomedcentral.com/ |47|-2180/8/202

(C) 2008 Roscetto et al; licensee BioMed Central Ltd.

This is an Open Access article distributed under the terms of the Creative Commons Attribution License (http://creativecommons.org/licenses/by/2.0), which permits unrestricted use, distribution, and reproduction in any medium, provided the original work is properly cited.

\begin{abstract}
Background: All bacterial genomes contain repetitive sequences which are members of specific DNA families. Such repeats may occur as single units, or found clustered in multiple copies in a head-to-tail configuration at specific loci. The number of clustered units per locus is a straindefining parameter. Assessing the length variability of clusters of repeats is a versatile typing methodology known as multilocus variable number of tandem repeat analysis (MLVA).
\end{abstract}

Results: Stenotrophomonas maltophilia is an environmental bacterium increasingly involved in nosocomial infections and resistant to most antibiotics. The availability of the whole DNA sequence of the S. maltophilia strain K279a allowed us to set up fast and accurate PCR-based diagnostic protocols based on the measurement of length variations of loci carrying a variable number of short palindromic repeats marking the $S$. maltophilia genome. On the basis of the amplimers size, it was possible to deduce the number of repeats present at 12 different loci in a collection of S. maltophilia isolates, and therefore label each of them with a digit. PCR-negative regions were labelled 0 . Coamplification of two pairs of loci provided a 4-digit code sufficient for immediate subtyping. By increasing the number of loci analyzed, it should be possible to assign a more specific digit profile to isolates. In general, MLVA data match genotyping data obtained by PFGE (pulsed-field gel electrophoresis). However, some isolates exhibiting the same PCR profiles at all loci display distinct PFGE patterns.

Conclusion: The utilization of the present protocol allows to type several S. maltophilia isolates in hours. The results are immediately interpretable without the need for sophisticated softwares. The data can be easily reproducible, and compared among different laboratories. 


\section{Background}

After years of debate regarding its appropriate taxonomic position, the nonfermentative, gram-negative bacillus previously known as Pseudomonas maltophilia or Xanthomonas maltophilia, has been definitively classified as Stenotrophomonas maltophilia [1]. This species is found in a wide variety of environments, and has been isolated from different sources, including water, sewage, soil and plant rhizosphere environments [2]. S. maltophilia is increasingly prevalent in hospitals, and is often isolated in hospitalized patients, as well as in cystic fibrosis (CF), burn, and immunosuppressed patients. The presence of $S$. maltophilia in CF patients is not associated with a worse clinical outcome. However, the organism contributes to chronic airway inflammation [3]. Moreover, in mixed infection formed in the CF lungs, S. maltophilia has been shown to influence the architecture of Pseudomonas aeruginosa biofilms by producing a diffusable signal factor [4].

S. maltophilia isolates exhibit high genetic diversity. Genotypic profiles have been determined by a variety of methods, including AFLP (amplified fragment length polymorphism) fingerprinting [5], RFLP (restriction fragment length polymorphism) analysis of the gyrase $\mathrm{B}$ gene [6] or the intergenic region between sme $\mathrm{D}$ and smeT genes [7], ERIC-PCR [8], and PFGE (pulsed-field gel electrophoresis) analysis of $\mathrm{Xba}$ I genomic digests [8-11].

Genome-wide analyses showed that in many bacterial genomes short DNA segments are amplified in tandem at specific chromosomal loci http://minisatellites.u-psud.fr. Changes in the number of repeats among isolates can be monitored by PCR, and MLVA (Multi locus variable number of tandem repeat analysis) surveys are widely used for subtyping purposes [12-19].

The sequence of the genome of the S. maltophilia strain K279a has been completed [20]. Genome inspection allowed us to set up a simple, fast and accurate PCR-based diagnostic protocol which relies on the measurement of length heterogeneity of specific intergenic regions of the $S$. maltophilia genome.

The present protocol allows typing several S. maltophilia isolates in hours. The assignment of a digit code to each isolate could be used to easily compare data among different laboratories.

\section{Results}

Specific sequence repeats punctuate the genome of $\mathrm{S}$. maltophilia

The whole DNA sequence of the $S$. maltophilia strain $\mathrm{K} 279 \mathrm{a}$ has been determined [20]. The genome is $4,851,126$ bp in length, and has an average $\mathrm{G}+\mathrm{C}$ content of $66.3 \%$. We found that the K279a chromosome hosts an abundant family of small, palindromic repeats fitting the consensus GTAGTGCCGGCCGCTGGCCGGCA (complementary residues are underlined) that we called SMAG (for Stenotrophomonas MAltophilia GTAG) because they carry the tetranucleotide GTAG at one terminus, similarly to small repetitive extragenic palindromic sequences (REPs) identified in the genomes of Escherichia coli and other microrganisms [21]. SMAGs make up approximately $0.5 \%$ of the K279a genome, and are spread throughout the chromosome either as single units, or in pairs, separated by $5-80$ bp long spacers. The size of the SMAG family allows to hypothesize that some of these repeats may function as regulatory signals either at the DNA or the RNA level, as shown for REPs [21].

\section{SMAGs and the PCR-based genotyping of S. maltophilia isolates}

In the K279a chromosome, monomeric and dimeric SMAGs are reiterated in tandem at multiple chromosomal loci, along with tracts of variable length of flanking DNA. We exploited the occurrence of SMAG arrays to set up PCR-based typing protocols, and focused our attention on 12 such loci, labelled I to XII in accord to their location on the K279a chromosome (Table 2). No rule in the pattern of amplification of SMAG sequences at the different loci could be discerned (Fig. 1A). Thus, region I features $50 \mathrm{bp}$ long repeats, resulting from the duplication of a monomeric 24 bp long SMAG along with 26 bp of flanking DNA. In contrast, region XII features repeats which are $103 \mathrm{bp}$ in length, and results from the duplication of a dimeric 72 bp SMAG and 31 bp of flanking DNA. In pilot experiments, regions IX and X were amplified by PCR from the DNA of the control strain K279a and five different S. maltophilia isolates. As shown in Fig. 1B, the size of the SMAG-positive regions varies, and this correlates with changes in the number of repeating units as confirmed by sequence analysis. Isolates could thus be marked by a digit corresponding to the number of SMAG repetitions present at a given locus (Fig. 1B). Prompted by these results, we monitored the twelve SMAG-positive loci by PCR. Analyses were carried out on DNAs derived from $38 \mathrm{~S}$. maltophilia strains, including the K279a strain, isolated from different sources (Table 1). On the basis of the amplimers size, it had been possible to deduce the number of repeats present at the loci in the various isolates, and therefore label each of them with a digit (Table 3). In some instances, we could not detect an amplification product for one or more loci in different isolates. PCR-negative regions were labelled 0 . To confirm our findings, alternative primers were used for some of these regions, but no reliable amplification product could be detected. The lack of amplification may reflect either an extensive polymorphism or deletions occurred in the regions analyzed. 
Table I: Source and origin of the S. maltophilia strains analyzed in this study

\begin{tabular}{|c|c|c|c|}
\hline strain name & source & location & reference \\
\hline 92 & bronchial aspirate (ICU) & UFH, Naples & {$[10]$} \\
\hline 262 & bronchial aspirate (CF) & UFH, Naples & {$[10]$} \\
\hline 527 & pharyngeal swab $(\mathrm{H})$ & UFH, Naples & [10] \\
\hline 528 & bronchial aspirate (ICU) & UFH, Naples & {$[10]$} \\
\hline 545 & bronchial aspirate (CF) & UFH, Naples & {$[10]$} \\
\hline 549 & bronchial aspirate (ICU) & UFH, Naples & {$[10]$} \\
\hline 571 & bronchial aspirate (ICU) & UFH, Naples & {$[10]$} \\
\hline 598 & pharyngeal swab $(\mathrm{H})$ & UFH, Naples & {$[10]$} \\
\hline 616 & pharyngeal swab $(\mathrm{H})$ & UFH, Naples & {$[10]$} \\
\hline 707 & bronchial aspirate $(C F)$ & UFH, Naples & {$[10]$} \\
\hline 714 & pharyngeal swab $(\mathrm{H})$ & UFH, Naples & {$[10]$} \\
\hline 915 & bronchial aspirate (ICU) & UFH, Naples & {$[10]$} \\
\hline 916 & bronchial aspirate (ICU) & UFH, Naples & {$[10]$} \\
\hline 1019 & ial aspirate (ICU) & UFH, Naples & {$[10]$} \\
\hline 1029 & bronchial aspirate (ICU) & UFH, Naples & {$[10]$} \\
\hline 1039 & bronchial aspirate (ICU) & UFH, Naples & {$[10]$} \\
\hline 1053 & urine (ICU) & UFH, Naples & {$[10]$} \\
\hline 1054 & bronchial aspirate (ICU) & UFH, Naples & {$[10]$} \\
\hline ОВGTC3 & pharyngeal swab (CF) & BGH, Rome & his study \\
\hline OBGTC9 & bronchial aspirate (CF) & BGH, Rome & {$[28]$} \\
\hline OBGTCIO & bronchial aspirate (CF) & BGH, Rome & [28] \\
\hline OBGTCI3 & bronchial aspirate (CF) & BGH, Rome & this study \\
\hline OBGTCI 6 & pharyngeal swab (CF) & BGH, Rome & [28] \\
\hline OBGTC20 & bronchial aspirate (CF) & BGH, Rome & [28] \\
\hline OBGTC22 & bronchial aspirate (CF) & BGH, Rome & this study \\
\hline OBGTC23 & bronchial aspirate (CF) & BGH, Rome & {$[28]$} \\
\hline OBGTC26 & pharyngeal swab (CF) & BGH, Rome & [28] \\
\hline OBGTC28 & bronchial aspirate (CF) & BGH, Rome & [28] \\
\hline OBGTC29 & bronchial aspirate (CF) & BGH, Rome & [28] \\
\hline OBGTC30 & bronchial aspirate (CF) & BGH, Rome & this study \\
\hline OBGTC45 & bronchial aspirate (CF) & BGH, Rome & this study \\
\hline OBGTC75 & bronchial aspirate (CF) & BGH, Rome & this study \\
\hline STM2 & emocolture $(H)$ & BGH, Rome & this study \\
\hline $\mathrm{K} 279 \mathrm{a}$ & emocolture (C) & BOU, Bristol & [20] \\
\hline LMG959 & rice paddy & Japan & this study \\
\hline LMGI0879 & rice paddy & Japan & this study \\
\hline LMGI087I & soil & Japan & this study \\
\hline OBG NI & soil & BGH, Rome & this study \\
\hline
\end{tabular}

CF, Cystic Fibrosis; ICU, Intensive Care Unit; H, Haematology; C (Cancer); UFH, University Federico II Hospital; BGH, Bambino Gesù Hospital; BOU, Bristol Oncology Unit. LMG-labeled strains are from the Laboratorium voor Microbiologie Gent Culture Collection, Belgium.

A few PCR products, derived from the amplification of regions VII, XI and XII, were slightly different in length, and could not be assigned to a size class. In these instances, amplimers were assigned to the nearest size class, and marked with the letters $\mathrm{a}, \mathrm{b}$ and $\mathrm{c}$ to denote size differences among them (Table 3 ). To clarify this issue, we determined the sequence of the PCR products derived by amplification of region VI in strains 915, 1029 and LMG959 (classified in Table 3 as $1 \mathrm{a}, 1 \mathrm{~b}$ and 1c, respectively). In the control strain K279a, region VI contains four SMAG dimers. In the 915 strain, the amplified DNA (1a amplimer) was similar to the K279a interval, but only one SMAG dimer was present. In the LMG959 strain, the region amplified (1c amplimer) was 45 bp shorter, because the SMAG dimer was replaced by a SMAG monomer. In strain 1029, the size change of region VI (1b amplimer) was due to replacement of the SMAG dimer and $10 \mathrm{bp}$ flanking sequence by a $66 \mathrm{bp}$ palindromic element, that is a member of a distinct, less abundant family of GTAG+ repeats in S. maltophilia. Thus, size variations of loci analyzed may correlate with recombinational events which replace SMAGs with members of the same family, or related DNA families.

In order to assess the stability of the SMAG-positive regions, the strains 528, 916 and 1039 were sub-cultured for 5 days, and the DNA extracted from single colonies of each strain was analyzed by PCR (data not shown). No changes in the pattern of amplification at loci III, IV, IX and XII were observed.

As shown in Table 3, the information derived from the survey of loci II, V, I and VII was sufficient to obtain a 4digit code, that assigned the 38 DNAs analyzed to 23 different PTs (PCR Types). Some strains, such as 528 and 571 , belong to the same PT type, and exhibited the same PCR profile at all the other loci. The same holds true for the three PT type 14 strains 916, 1019 and 1053, and for 3 out of 7 of the PT-19 strains. In contrast, strains 714 an 262 belong to different PTs (17 and 19, respectively), but, aside from differences in region VII, were identical at all loci.

The finding that a comparatively relatively robust typing can be achieved by analysing only the four loci II, V, I and VII, highlighted in Table 3, is relevant, mostly in view of the fact that they can be co-amplified in pairs. In both instances, the amplimers corresponding to either locus can be easily distinguished because of their size range, allowing an immediate typing (Fig. 2).

\section{PFGE-typing of S. maltophilia isolates}

PFGE is the gold standard for strain genotyping also for $S$. maltophilia. PCR data shown in Table 3 partially complemented genotyping data obtained by PFGE. OBGTC9 and OBGTC10 strains exhibited the same PCR profile at all the SMAG-positive regions analyzed, and their PFGE profiles are undistinguishable (Fig. 3). Strains 916, 1019 and 1053, which belong to PFGE A-type, and strains 528 and 571, which belong to PFGE B-type (data not shown; for the PFGE relatedness of these strains, see Crispino et al., 2002) similarly exhibited the same PCR profile at all the loci (Table 3). Other strains exhibited similar PCR profiles, but different PFGE patterns. XbaI digests of OBGTC13, OBGTC23 and OBGTC30 DNAs produced undistinguishable PFGE patterns. Their PCR profiles were similar on the whole, but OBGTC23 featured a PCR type different from 
Table 2: Loci analyzed by PCR in S. maltophilia strains

\begin{tabular}{|c|c|c|c|}
\hline locus & coordinates & PCR primers & $\mathbf{T a}$ \\
\hline \multirow[t]{2}{*}{$\mathbf{I}$} & $0078 \mid 53-0078502$ & f [0077906] CACCGCCGAGTGCGATGCCGATCTT & $69^{\circ} \mathrm{C}$ \\
\hline & & $\mathrm{r}[007875 \mathrm{I}]$ ACCCGACCGTGGACATGGACGTGCG & \\
\hline \multirow[t]{2}{*}{ II } & $0458218-0458270$ & f [0458I22] GACGTGAAGTGGCTGCGCCTGAAGC & $65^{\circ} \mathrm{C}$ \\
\hline & & r [0458343] CGTTCCAGCCACTGTACCGCCACCA & \\
\hline \multirow[t]{2}{*}{ III } & $0898001-0898182$ & f [0897802] GTGGTGGTGATCAAGCGCGGCAAGG & $68^{\circ} \mathrm{C}$ \\
\hline & & r [0898549] GGCAGGTCGGCTGGATGGCGGTACT & \\
\hline \multirow[t]{2}{*}{ IV } & $1260576-1260695$ & f [1260393] CAGGAACGATGTGCGGGCAGTGACC & $66^{\circ} \mathrm{C}$ \\
\hline & & $\mathrm{r}[1260806]$ CTGTCCGAAACACATGGCGTGGCAG & \\
\hline \multirow[t]{2}{*}{$\mathbf{v}$} & |397805-1398345 & f [1397652] TGATCGGCATCATCGTGGTCGGTAC & $65^{\circ} \mathrm{C}$ \\
\hline & & $\mathrm{r}[1398470]$ GCGAGTACCTGAGCGAACTGGGGTG & \\
\hline \multirow[t]{2}{*}{ VI } & $2363422-2363811$ & $f[23633 \mid 4]$ CAGCATCATCAACAAGCACCATGGC & $65^{\circ} \mathrm{C}$ \\
\hline & & $\mathrm{r}[2363972]$ TATCGCTTCCTGACCAAACCGTGGA & \\
\hline \multirow[t]{2}{*}{ VII } & $2877734-2877879$ & f [2877624] GCCGCTGGTCTGGCCGTTGATGATG & $65^{\circ} \mathrm{C}$ \\
\hline & & r [2877987] GCTGGAGCTGCACCTGAGCGCCTGG & \\
\hline \multirow[t]{2}{*}{ VIII } & $28937 \mid 3-2894397$ & f [2893497] TGGACCGCCACCGACTACCTGATGG & $67^{\circ} \mathrm{C}$ \\
\hline & & $\mathrm{r}[2894486]$ CACCACCACCACCGAGGTCTACCCG & \\
\hline \multirow[t]{2}{*}{$\mathbf{I X}$} & $3626782-3627370$ & f [3626652] CGAGTACTTCACCCCGGTCAACGAG & $65^{\circ} \mathrm{C}$ \\
\hline & & $\mathrm{r}$ [3627448] AGGGCCAGACCTTCGAGGAATTCAA & \\
\hline \multirow[t]{2}{*}{$x$} & $3842432-3842620$ & f [3842338] TGGTGGTCAATGATGGGCAGCCGGA & $66^{\circ} \mathrm{C}$ \\
\hline & & r [384273I] CCGCCACGATGACTGGTCTCAGCCG & \\
\hline \multirow[t]{2}{*}{$\mathbf{X} \mathbf{I}$} & $4475729-4476245$ & f [4475549] CACAGGTCACACAGCGTGGTGTACG & $65^{\circ} \mathrm{C}$ \\
\hline & & r [4476369] GGTTGTTCGGCATCGGTTTGATCAT & \\
\hline \multirow[t]{2}{*}{$\mathbf{X I I}$} & $4528877-4529176$ & f [4528752] CGCCATCCAGCCGTCCTGTACTGCT & $66^{\circ} \mathrm{C}$ \\
\hline & & r [4529342] GGCGGGTTGGGTGGGTACTACCTGG & \\
\hline
\end{tabular}

The coordinates of the loci on the genome of the K279a strain, the forward ( $f$ ) and reverse ( $r$ ) primers in the $5^{\prime}-3^{\prime}$ orientation, their $5^{\prime}$ end position, and the annealing temperatures $(\mathrm{Ta})$ are shown.

OBGTC13 and OBGTC30 (PT-10 vs PT-13), and the three isolates differed from each other at multiple additional loci. Moreover, K279a DNA was identical to OBGTC9 and OBGTC10 DNAs at all SMAG loci, but clearly differed from both DNAs when analyzed by PFGE (Fig. 3).

\section{Discussion}

The MLVA technique involves amplification and size analysis of polymorphic DNA regions containing variable numbers of tandemly repeated sequences, and is an established method to classify isolates of microbial species for which complete genome information is available [22]. The determination of the complete genome sequence of the S. maltophilia K279a strain allowed us to set up a MLVA assay also for this organism.

All the approaches so far utilized for the genotyping of $S$. maltophilia clinical isolates have led to the conclusion that
S. maltophilia strains are highly heterogeneous [5-11]. According to AFLP fingerprinting [5] and gyrB RFLP [6] analysis, S. maltophilia can be assigned to 8-10 genomic groups. The majority of CF isolates grouped in two clusters [6], suggesting that isolates of specific groups have an increased potential for the colonization of the respiratory tract of CF patients. Considering the interest paid to $S$. maltophilia as an emerging opportunistic pathogen associated with nosocomial infections, we wanted to develop a fast, accurate and unexpensive method of genotyping which could be adopted for strain classification and comparisons. The chromosomal regions carrying clusters of SMAGs, an abundant sequence repeat spread in the $S$. maltophilia genome, vary in size among isolates, allowing MLVA-based typing surveys. The repeat units found at the various loci analyzed are sufficiently large to discriminate length variation among isolates by low molecular weight agarose gel electrophoresis. In most instances, PCR data 
Table 3: PCR analysis of SMAG+ loci in S. maltophilia strains.

\begin{tabular}{|c|c|c|c|c|c|c|c|c|c|c|c|c|c|}
\hline \multirow[t]{2}{*}{ strains } & \multicolumn{12}{|c|}{ loci } & \multirow[t]{2}{*}{ PCR Type } \\
\hline & II & V & 1 & VII & IX & III & VIII & VI & XII & $X I$ & $x$ & IV & \\
\hline OBGTC28 & I & 0 & 2 & 2 & 1 & 2 & I & la & I & 0 & 0 & 0 & PT-I \\
\hline LMG959 & $\mathbf{I}$ & 0 & 2 & 2 & 0 & I & 0 & Ic & 2 & 0 & 0 & 0 & \\
\hline 1054 & I & I & 0 & 4 & 1 & I & 0 & Ic & I & $\mathrm{Ib}$ & 0 & 0 & PT-2 \\
\hline OBG NI & I & I & 0 & 3 & 1 & 5 & I & la & I & 0 & 0 & 0 & PT-3 \\
\hline 1029 & I & I & I & 2 & 1 & I & 0 & $\mathrm{Ib}$ & I & $\mathrm{lb}$ & 0 & 0 & PT-4 \\
\hline 1039 & I & I & I & 2 & 1 & I & 0 & $\mathrm{Ib}$ & I & $\mathrm{Ib}$ & 1 & 2 & \\
\hline 616 & I & I & 2 & 2 & 0 & 0 & 0 & 0 & 0 & 0 & 0 & 0 & PT-5 \\
\hline 707 & I & I & 2 & 2 & 1 & 0 & 0 & 8 & 0 & 0 & 0 & 0 & \\
\hline LMG 10879 & I & i & 3 & 2 & 0 & I & 0 & 0 & 0 & 0 & 17 & 0 & PT-6 \\
\hline OBGTC22 & 2 & 0 & 0 & 0 & 0 & 0 & 0 & 0 & 0 & 0 & 4 & 0 & PT-7 \\
\hline LMG I087I & 2 & 0 & 0 & 3 & 0 & 0 & I & 2 & 0 & 0 & 0 & 0 & PT-8 \\
\hline 92 & 2 & 0 & 4 & 2 & I & I & I & la & I & 2 & 0 & 2 & PT-9 \\
\hline 549 & 2 & I & 0 & 2 & I & 0 & 0 & Ic & I & 0 & 0 & 0 & PT-10 \\
\hline 598 & 2 & I & 0 & 2 & 2 & 6 & I & 4 & 4 & la & 4 & 2 & \\
\hline OBGTC23 & 2 & I & 0 & 2 & 1 & 2 & I & la & I & 2 & 0 & 0 & \\
\hline STM2 & 2 & I & 2 & 2 & I & I & 1 & 2 & I & la & 4 & 0 & PT-II \\
\hline OBGTC75 & 2 & I & 3 & I & 4 & 2 & I & $\mathrm{Ib}$ & I & 4 & 0 & 2 & PT-12 \\
\hline OBGTCI3 & 2 & I & 4 & 2 & I & 2 & 1 & la & I & 2 & 4 & 0 & PT-13 \\
\hline OBGTC 30 & 2 & I & 4 & 2 & 1 & 2 & 1 & la & 0 & 0 & 0 & 0 & \\
\hline 916 & 2 & 3 & 3 & 2 & 1 & 1 & 4 & 8 & 2 & 4 & 1 & 2 & PT-I4 \\
\hline 1019 & 2 & 3 & 3 & 2 & I & I & 4 & 8 & 2 & 4 & 1 & 2 & \\
\hline 1053 & 2 & 3 & 3 & 2 & I & I & 4 & 8 & 2 & 4 & 1 & 2 & \\
\hline 527 & 2 & 3 & 7 & 4 & 4 & I & 3 & la & 4 & 4 & 4 & 4 & PT-I5 \\
\hline OBGTC29 & 2 & 4 & 7 & I & 2 & 2 & 4 & 3 & 4 & 3 & 15 & 2 & PT-16 \\
\hline 714 & 2 & 4 & 7 & 2 & 2 & 3 & 4 & 6 & 2 & 4 & 5 & 3 & PT- 17 \\
\hline 545 & 2 & 4 & 7 & 3 & 2 & 2 & 4 & 3 & $3 a$ & 3 & 15 & 2 & PT-18 \\
\hline 262 & 2 & 4 & 7 & 4 & 2 & 3 & 4 & 6 & 2 & 4 & 5 & 3 & PT-19 \\
\hline 915 & 2 & 4 & 7 & 4 & 2 & 3 & 4 & $\mathrm{la}$ & 2 & 3 & 5 & 4 & \\
\hline $\mathrm{K} 279 \mathrm{a}$ & 2 & 4 & 7 & 4 & 4 & 3 & 4 & 4 & $3 b$ & 4 & 3 & 4 & \\
\hline OBGTC9 & 2 & 4 & 7 & 4 & 4 & 3 & 4 & 4 & $3 b$ & 4 & 3 & 4 & \\
\hline OBGTCIO & 2 & 4 & 7 & 4 & 4 & 3 & 4 & 4 & $3 b$ & 4 & 3 & 4 & \\
\hline OBGTC20 & 2 & 4 & 7 & 4 & 4 & 3 & 4 & la & 4 & 4 & 3 & 2 & \\
\hline OBGTC26 & 2 & 4 & 7 & 4 & 2 & I & 4 & 6 & 2 & 4 & 5 & 4 & \\
\hline 528 & 2 & 5 & 3 & 3 & 4 & 2 & 4 & 5 & 5 & la & 5 & 4 & PT-20 \\
\hline 571 & 2 & 5 & 3 & 3 & 4 & 2 & 4 & 5 & 5 & la & 5 & 4 & \\
\hline OBGTCI 6 & 2 & 5 & 5 & 4 & 5 & 3 & 3 & 7 & $3 a$ & 3 & 4 & 4 & PT-2I \\
\hline OBGTC3 & 2 & 5 & 10 & 2 & 5 & 3 & 3 & 9 & $3 a$ & 3 & 4 & 3 & PT-22 \\
\hline OBGTC45 & 2 & 5 & 10 & 4 & 5 & 0 & 3 & 9 & $3 a$ & 0 & 15 & 5 & PT-23 \\
\hline
\end{tabular}

The PCR products derived from the amplification of loci I to XII in the listed strains are labeled with the number of SMAG repeats present. The letters $\mathrm{a}, \mathrm{b}$ and $\mathrm{c}$ denote length differences among amplimers assigned to the same class. The lack of amplification is labeled by zero. PCR types (PTs) are defined by the 4-digit code resulting from analyses of loci II, V, I and VII (bold numbers). Strains with the same PT are boxed.

enabled to set a direct correlation between the length of the amplimers and the number of SMAG repeats present at the analyzed loci. The latter could be directly marked by the number of repeats, setting the basis for a simple, numerical classification of the strains analysed. Broad sorting of a large number of isolates may suggest to restrict MLVA analyses to a few SMAG-positive loci. Allelic variants of the four loci II, V, I and VII (Table 3) are detectable by two PCR co-amplifications reaction, providing 4-digit typing profiles which could turn out to be effective for simple typing purposes. By increasing the number of loci analyzed, it could be possible to obtain a more discriminating digit profile, as in MLST analyses [23].
According to our typing scheme, regions not responding to the PCR approach have been assigned the digit 0 . While uninformative on the integrity of the region under scrutiny, the lack of amplification of a certain locus is fully exploitable in a multi-typing system. A "caveat" may be represented by cases in which it is not possible to immediately correlate the size of the amplicon with the number of repeats as observed for amplimers slightly differing in length occasionally found at loci VII, XI and XII. However, this could represent a problem in the analyses of large populations of isolates, calling for a highly discriminating profiling. Minor size differences among amplicons allow discrimination for typing purposes as the major ones, and 

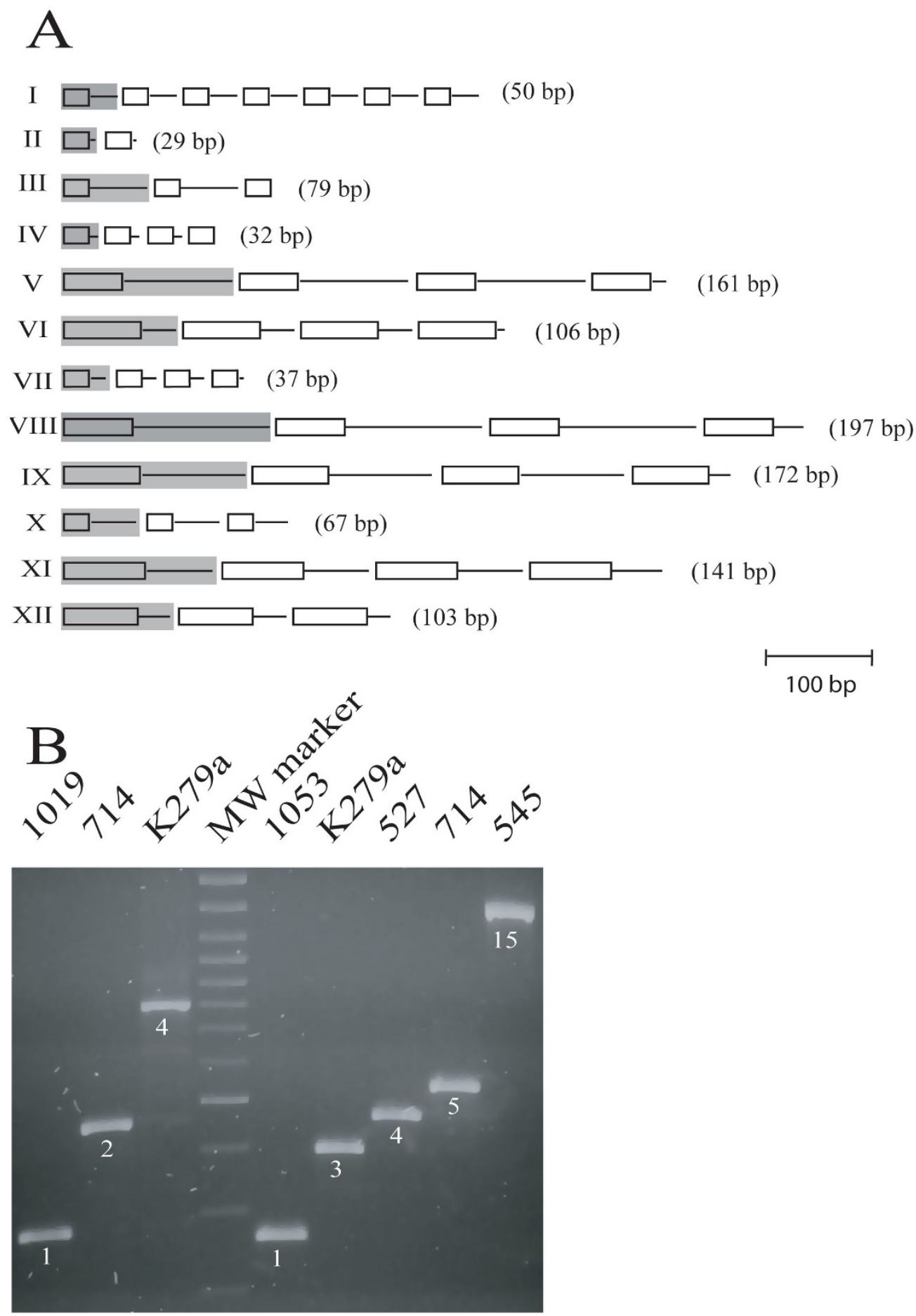

locus IX locus X

Figure I

A) Organization of the repetitive SMAG-positive loci in the genome of the S. maltophilia K279a strain. The structure of loci I to XII is diagramatically shown. SMAG sequences are represented as boxes. Repeat units at each locus are highlighted and their size in bp is indicated. B) Allelic variations at SMAG ${ }^{+}$loci. Amplimers spanning the loci IX and X derived from the DNA of the indicated S. maltophilia strains were electrophoresed on a $2 \%$ agarose gel. Numbers below bands mark the number of repeat units within each amplimer. The 100 bp ladder was used as molecular weight (MW) DNA marker. 

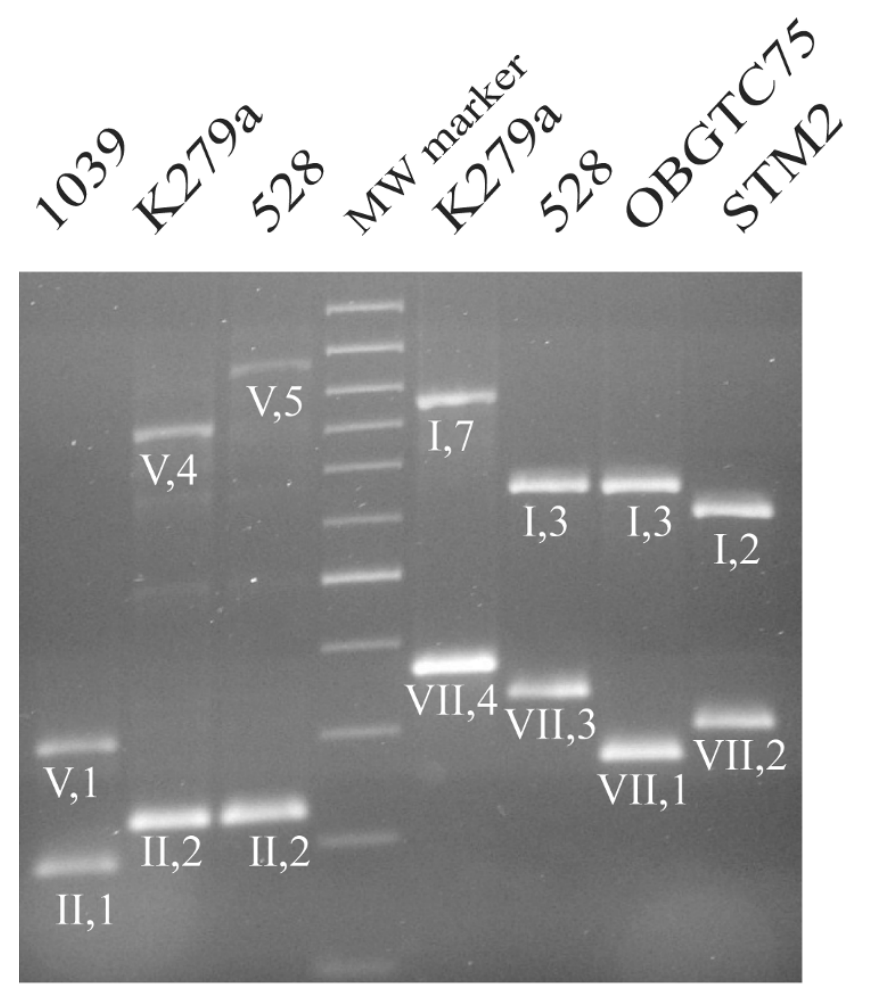

\section{loci $\mathrm{II}+\mathrm{V} \quad$ loci $\mathrm{I}+\mathrm{VII}$}

Figure 2

Co-amplification of SMAG-positive loci. Amplimers deriving from the dual amplification of II and V, and I and VII loci from the DNA of the indicated strains were analyzed by elctrophoresis as in Fig. I.

can be indicated by marking amplimers also with letters. However, accurate measuring of small size differences among amplimers which have been analyzed in different electrophoretic runs may be cumbersome. Thus, it would be advisable to assign to amplicons which may slightly differ in size the same digit, which should correspond to the most likely number of repeats present. This may ensure to rapidly proceed in classifying the different isolates, eventually further distinguishing them by means of additional analyses.

MLVA assays provide results that parallel PFGE data, although some differences have been noticed, since MLVA and PFGE measure different types of chromosomal modifications, and, for example, recombination events within a genome could be detected by PFGE, but overlooked by MLVA analyses $[18,24,25]$. The same holds true in our study, as strains such as K279a, OBGTC9 and OBGTC10, while identical according to MLVA data, differ when analyzed by PFGE. The method we have devised is simpler, less time-consuming and economically more advanta- geous than PFGE. As suggested by Tenover et al. [25], MLVA approaches could be particularly helpful to identify strains responsible for outbreaks in hospital settings, and to determine the relatedness of isolates collected over short periods of time. In contrast, PFGE could be priviliged for long time period analyses of bacterial populations.

\section{Conclusion}

The utilization of the present protocol will be useful for fast and efficient typing purposes. Several S. maltophilia isolates could be typed in hours, and the results interpreted de visu without the need for sophisticated software. Data would be easily reproducible, and immediately comparable among different laboratories.

\section{Methods}

\section{S. maltophilia strains}

S. maltophilia strains analyzed in this study are listed in Table 1. Clinical isolates were identified as S. maltophilia by using the VITEK II system (bioMerieux, Morey-l'Etoile, France). The identification was confirmed by PCR amplification and sequence analysis of the $16 \mathrm{~S}$ rDNA. Strains were routinely grown in brain heart infusion at $37^{\circ} \mathrm{C}$, except for the environmental strains LMG959, LMG10871, LMG10879 and OBGN1 which were grown at $30^{\circ} \mathrm{C}$. In order to analyze the stability of the genomic regions under scrutiny, a few strains were sub-cultured in brain heart infusion at $37^{\circ} \mathrm{C} 5$ times for $18-24$ hrs.

\section{PCR amplification}

The DNA of single colonies derived from the final subcultures was analyzed by PCR amplification of DNA regions of interest. Genomic DNA was extracted as described by De Gregorio et al. [26]. PCR reactions were carried out by incubating $20 \mathrm{ng}$ of DNA with $160 \mathrm{ng}$ of each primer in the presence of dXTPs (200 nanomoles), $1.5 \mathrm{mM}$ magnesium chloride and the Taq DNA polymerase Recombinant (Invitrogen). Because of the high GC content of the S. maltophilia genome (> 66\%), all PCR reactions were carried out in GC-rich buffer (Roche). The oligomers used as primers, and the annealing temperatures, are listed in Table 2. Samples were incubated at $95^{\circ} \mathrm{C}$ for $5^{\prime}$, and subsequently for $1^{\prime}$ at $95^{\circ} \mathrm{C}, 1^{\prime}$ at the annealing temperature and $1^{\prime}$ at $72^{\circ} \mathrm{C}$, for a total of 30 cycles. At the end of the cycle, samples were kept at $72^{\circ} \mathrm{C}$ for 7 ' before harvesting.

PCR products were electrophoresed on 1.5-2\% agarose gels in $0.5 \times$ TBE buffer ( $45 \mathrm{mM}$ Tris $\mathrm{pH} 8,45 \mathrm{mM}$ Borate, $0.5 \mathrm{mM}$ EDTA) at $120 \mathrm{~V}$ (constant voltage). The $100 \mathrm{bp}$ ladder (Fermentas) was used as molecular weight marker.

\section{PFGE analysis}

Preparation of agarose plugs containing chromosomal DNA for PFGE analysis was performed using the PulseNet 
$\%$ similarity

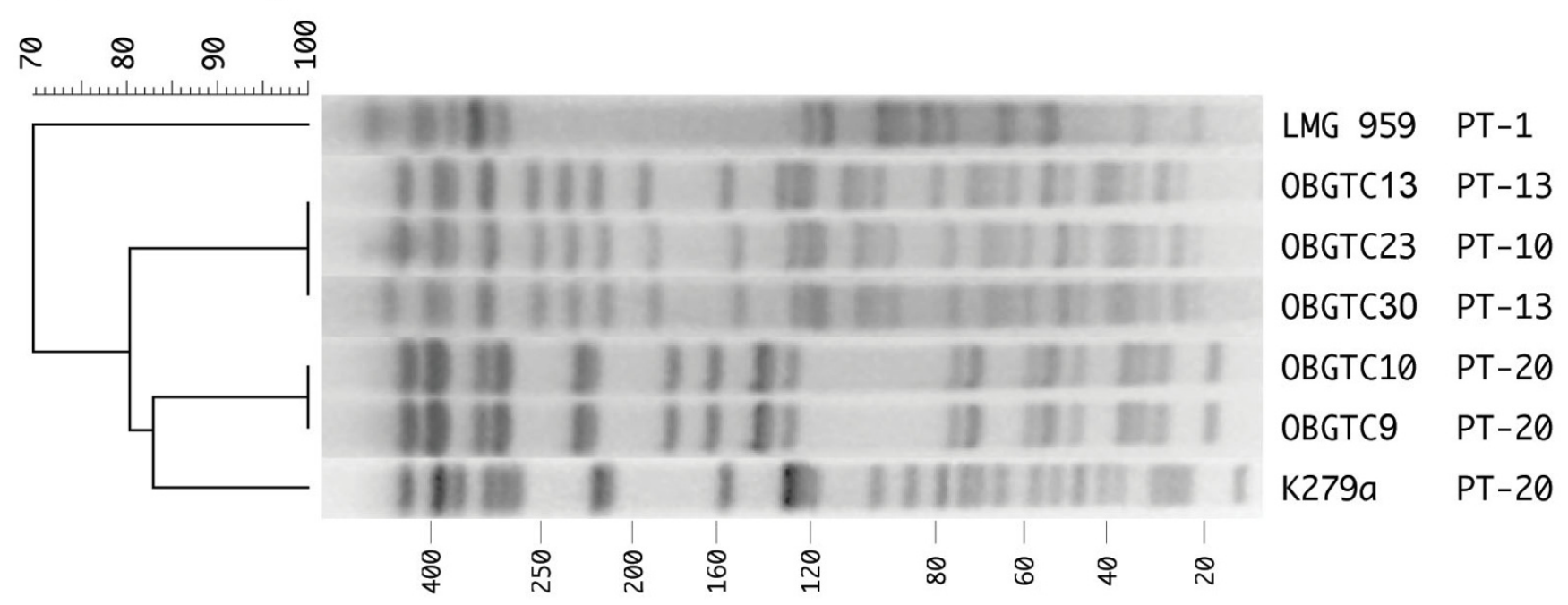

Figure 3

PFGE profiles of $\mathbf{S}$. maltophilia strains. The DNA of the indicated isolates was restricted with Xbal. The digestion products were resolved on I.2\% agarose gels (see Methods). The percentage genetic similarity is shown above the dendrogram. Strain numbers and PT types are shown on the right of each PFGE profile. Numbers at the bottom refer to the size in kb of the MW DNA.

standardized procedure http://www.cdc.gov/pulsenet The DNA plugs were digested with $60 \mathrm{U}$ of $\mathrm{XbaI}$ (Roche Diagnostics) at $37^{\circ} \mathrm{C}$ fo $16 \mathrm{~h}$. Genomic DNA fragments were separated by PFGE at $14^{\circ} \mathrm{C}$ on agarose $1.2 \% \mathrm{w} / \mathrm{v}$ gels in a clamped homogeneous field electrophoresis apparatus (CHEF-DRII system; Bio-Rad, Hemel Hempstead, UK), with pulse times ramped from 1 to $20 \mathrm{~s}$ over $21 \mathrm{~h}$ at $6.0 \mathrm{~V} /$ $\mathrm{cm}$ in $0.5 \times$ TBE. DNA fragments obtained from $\mathrm{XbaI}$ digestion of plugs containing chromosomal DNA of Salmonella braenderup strain H9B12 were used as molecular weight markers [27].

Electrophoretic patterns were analyzed by UPGMA (Unweighted Pair Group Method with Arithmetic mean) using the Gel Compar II version 4.5 software (Applied Maths).

\section{Authors' contributions}

ER and FR designed the PCR oligomers and carried out the DNA analyses, BC, MC and RF provided the S. maltophilia strains and performed the PFGE experiments, PPDN conceived the study and participated in its design and coordination, MSC and PPDN drafted the manuscript. All authors read and approved the final manuscript.

\section{Acknowledgements}

We are indebted to M.B. Avison for K279a strain and E. Fiscarelli for strains of the OBG collection. Research was supported in part by grant FFC 7/2007 of the Italian Cystic Fibrosis Research Foundation to BC and MC.

\section{References}

I. Palleroni NJ, Bradbury JF: Stenotrophomonas, a new bacterial genus for Xanthomonas maltophilia (Hugh 1980) Swings et al. 1983. Int J Syst Bacteriol 1993, 43:606-609.

2. Denton M, Kerr KG: Microbiological and clinical aspects of infection associated with Stenotrophomonas maltophilia. Clin Microbiol Rev 1998, I I:57-80.

3. Waters VJ, Gómez MI, Soong G, Amin S, Ernst RK, Prince A: Immunostimulatory properties of the emerging pathogen Stenotrophomonas maltophilia. Infect Immun 2007, 75:1698-I703.

4. Ryan RP, Fouhy Y, Garcia BF, Watt SA, Niehaus K, Yang L, TolkerNielsen T, Dow JM: Interspecies signalling via the Stenotrophomonas maltophilia diffusible signal factor influences biofilm formation and polymyxin tolerance in Pseudomonas aeruginosa. Mol Microbiol 2008, 68:75-86.

5. Hauben L, Vauterin L, Moore ERB, Hoste B, Swings J: Genomic diversity of the genus Stenotrophomonas. Int J Syst Bacteriol 1999, 49:1749-1760.

6. Coenye T, Vanlaere E, LiPuma JJ, Vandamme P: Identification of genomic groups in the genus Stenotrophomonas using gyrB RFLP analysis. FEMS Immunol Med Microbiol 2004, 40: I8I-185.

7. Gould VC, Okazaki A, Howe RA, Avison MB: Analysis of sequence variation among sme DEF multi drug efflux pump genes and flanking DNA from defined I6S rRNA subgroups of clinical Stenotrophomonas maltophilia isolates. J Antimicrob Chemother 2004, 54:348-353.

8. Gylmez D, Hascelik G: Stenotrophomonas maltophilia : antimicrobial resistance and molecular typing of an emerging pathogen in a Turkish university hospital. Clin Microbiol Infect 2005, I I:880-886.

9. Yao JDC, Conly JM, Krajden M: Molecular typing of Stenotrophomonas (Xanthomonas) maltophilia by DNA macrorestriction analysis and random amplified polymorphic DNA analysis. J Clin Microbiol 1995, 33:2195-2198.

10. Crispino M, Boccia MC, Bagattini M, Villari P, Triassi M, Zarrilli R: Molecular epidemiology of Stenotrophomonas maltophilia in a university hospital. J Hosp Infect 2002, 52:88-92.

II. Valdezate S, Vindel A, Martin-Davila P, Del Saz BS, Baquero F, Canton R: High genetic diversity among Stenotrophomonas maltophilia strains despite their originating at a single hospital. J Clin Microbiol 2004, 42:693-699. 
12. Onteniente L, Brisse S, Tassios PT, Vergnaud G: Evaluation of the polymorphisms associated with tandem repeats for Pseudomonas aeruginosa strain typing. J Clin Microbiol 2003, 4I:499|-4997.

13. Allix C, Supply P, Fauville-Dufaux M: Utility of fast mycobacterial interspersed repetitive unit-variable number tandem repeat genotyping in clinical mycobacteriological analysis. Clin Infect Dis 2004, 39:783-789.

14. Lindstedt BA, Vardund T, Aas L, Kapperud G: Multiple-locus variable-number tandem-repeats analysis of Salmonella enterica subsp. Enterica serovar Typhimurium using PCR multiplexing and multicolor capillarelectrophoresis. J Microbiol Methods 2004, 59:163-172.

15. Schouls LM, Heide HG van der, Vauterin L, Vauterin P, Mooi FR: Multiple-locus variable-number tandem repeat analysis of Dutch Bordetella pertussis strains reveals rapid genetic changes with clonal expansion during the late 1990s. J Bacteriol 2004, I 86:5496-5505.

16. Koeck JL, Njanpop-Lafourcade BM, Cade S, Varon E, Sangare L, Valjevac S, Vergnaud G, Pourcel C: Evaluation and selection of tandem repeat loci for Streptococcus pneumoniae MLVA strain typing. BMC Microbiol 2005, 5:66..

17. Yazdankhah SP, Lindstedt BA, Caugant DA: Use of variablenumber tandem repeats to examine genetic diversity of Neisseria meningitidis. J Clin Microbiol 2005, 43:1699-1705.

18. Johansson A, Koskiniemi S, Gottfridsson P, Wistrom J, Monsen T: Multiple-locus variable-number tandem repeat analysis for typing of Staphylococcus epidermidis. J Clin Microbiol 2006, 44:260-265.

19. Cho S, Boxrud DJ, Bartkus JM, Whittam TS, Saeed M: Multiple-locus variable-number tandem repeat analysis of Salmonella Enteritidis isolates from human and non-human sources using a single multiplex PCR. FEMS Microbiol Lett 2007, 275: $16-23$.

20. Crossman LC, Gould VC, Dow JM, Vernikos GS, Okazaki A, Sebaihia $M$, Saunders D, Arrowsmith C, Carver T, Peters N, Adlem E, Kerhornou A, Lord A, Murphy L, Seeger K, Squares R, Rutter S, Quail MA, Rajandream MA, Harris D, Churcher C, Bentley SD, Parkhill J, Thomson NR, Avison MB: The complete genome, comparative and functional analysis of Stenotrophomonas maltophilia reveals an organism heavily shielded by drug resistance determinants. Genome Biol 2008, 9:R74.

21. Tobes R, Pareja E: Repetitive extragenic palindromic sequences in the Pseudomonas syringae pv. tomato DC3000 genome: extragenic signals for genome reannotation. Res Microbiol 2005, I 56:424-433.

22. van Belkum A: Tracing isolates of bacterial species by multi locus variable number of tandem repeat analysis (MLVA). FEMS Immunol Med Microbiol 2007, 49:22-27.

23. Maiden MC: Multi locus sequence typing of bacteria. Annu Rev Microbiol 2006, 60:56I-588.

24. Malachowa N, Sabat A, Gniadkowski M, Krzyszton-Russjan J, Empel J, Miedzobrodzki J, Kosowska-Shick K, Appelbaum PC, Hryniewicz W: Comparison of multiple-locus variable-number tandemrepeat analysis with pulsed-field gel electrophoresis, spa typing, and multi locus sequence typing for clonal characterization of Staphylococcus aureus isolates. J Clin Microbiol 2005, 43:3095-3100.

25. Tenover FC, Vaughn RR, McDougal LK, Fosheim GE, McGowan JE Jr: Multiple-locus variable-number tandem-repeat assay analysis of methicillin-resistant Staphylococcus aureus strains. J Clin Microbiol 2007, 45:2215-2219.

26. De Gregorio E, Silvestro G, Venditti R, Carlomagno MS, Di Nocera PP: Structural organization and functional properties of miniature DNA insertion sequences in Yersiniae. J Bacteriol 2006, I 88:7876-7884.

27. Hunter SB, Vauterin P, Lambert-Fair MA, van Duyne MS, Kubota K, Graves L, Wrigley D, Barrett T, Ribot E: Establishment of a universal size standard strain for use with the PulseNet standardized pulsed-field gel electrophoresis protocols: converting the national databases to the new size standard. J Clin Microbiol 2005, 43: 1045-1050.

28. Di Bonaventura G, Prosseda G, Del Chierico F, Cannavacciuolo $S$, Cipriani P, Petrucca A, Ammendolia MG, Concato C, Fiscarelli E, Casalino M, Piccolomini R, Nicoletti M, Colonna B: Molecular characterization of virulence determinants of Stenotrophomonas maltophilia strains isolated from patients affected by cystic fibrosis. Int J Immunopathol Pharmacol 2007, 20:529-537.
Publish with Bio Med Central and every scientist can read your work free of charge

"BioMed Central will be the most significant development for disseminating the results of biomedical research in our lifetime. "

Sir Paul Nurse, Cancer Research UK

Your research papers will be:

- available free of charge to the entire biomedical community

- peer reviewed and published immediately upon acceptance

- cited in PubMed and archived on PubMed Central

- yours - you keep the copyright

Submit your manuscript here:

http://www.biomedcentral.com/info/publishing_adv.asp 